\title{
La minería de plata y cobre en el Distrito Sur de la Baja California: el proceso de urbanización en El Triunfo y Santa Rosalía durante la época porfiriana
}

Edith González Cruz*
Ignacio Rivas Hernández

Fecha de recepción: 1 de diciembre de 2017. Fecha de aceptación: 30 de mayo de 2018

\section{Resumen}

En este estudio se aborda el proceso de urbanización en El Triunfo y Santa Rosalía durante el periodo porfiriano, poblaciones pertenecientes a lo que hoy es el estado de Baja California Sur, cuyo nacimiento se debió al desarrollo de la minería de plata y cobre, respectivamente. Aunque El Triunfo tuvo su origen en la época colonial y Santa Rosalía a fines de la centuria del XIX, ambas poblaciones cambiaron su rostro demográfico y estructural durante el gobierno de Porfirio Díaz, como consecuencia de la modernización minera que trajo el capital extranjero pero con algunas peculiaridades que respondieron a su propio nacimiento.

Silver and copper mining in South District of Baja California: the urbanization process at El Triunfo and Santa Rosalia during the Porfirian era

\footnotetext{
Abstract

This study is about the urbanization process at El Triunfo and Santa Rosalia during the Porfinian era; both towns belonged to what nowadays is Baja California South and they were born due to the development of silver and copper mining respectively. Although El Triunfo began during the colonial period and Santa Rosalía by late $19^{\text {th }}$ century both of them changed their demographic

Palabras clave

El Triunfo

Santa Rosalía urbanización minería

Key words

El Triunfo Santa Rosalía urbanization mining 
and structural appearance during the government of Porfirio Diaz, as a result of the mining modernization process brought by foreign capital -even when certain peculiarities responded to their own growth.

1. Veánse Vries (1987), Clark (1982), Morse (1971), Sánchez de Tagle et al. (1998) y Pipitone (2003)
Como preámbulo al presente trabajo, que es explicar el proceso de urbanización en los pueblos mineros de El Triunfo y Santa Rosalía durante la época porfiriana -pertenecientes a lo que hoy es el estado de Baja California Sur, ubicado en el noroeste de México (Figura 1)- es pertinente indicar que las investigaciones que abordan la temática minera en esa región del sur peninsular se han centrado fundamentalmente en examinar el establecimiento y desarrollo de las dos principales empresas que fueron responsables del proceso de modernización de la actividad minera: El Progreso, de capital estadounidense, que se estableció en El Triunfo para la extracción y beneficio de la plata; y El Boleo, de inversión francesa, que dio vida al pueblo de Santa Rosalía, donde se dedicó a la explotación y beneficio del cobre; la relación de éstas con los trabajadores y autoridades de los ámbitos distrital y federal así como el impacto económico y político que provocaron en la región donde se fincaron. Entre los autores que han abordado estas investigaciones se encuentran: Edith González Cruz (1985, 2000, 2016), Juan Manuel Romero Gil (1991 y 2001), Ignacio Rivas Hernández (2000) y Dennis Kortheuer (2001). Desde una hechura regional, los mencionados autores han dado cuenta de la importancia que tuvo la minería en la colonización y el desarrollo de una economía de mercado en una región periférica, como lo era la península de Baja California. Engrosando, así, los estudios historiográficos sobre la minería en México, que hasta los años setenta del siglo anterior eran restringidos, "especialmente en lo que se refiere a obras generales de interpretación" (Herrera, 1998: 171). Además, como reflejo de la historiografía occidental, desde fines de la centuria pasada se han ido abriendo otros campos en el quehacer histórico nacional, entre éstos está el de la perspectiva urbana (De Gortari, 1990), con énfasis en el periodo porfiriano, el cual se caracterizó por un crecimiento demográfico importante que transformó el escenario de algunas ciudades y dio pie al surgimiento de otras. En esta perspectiva, que comenzó dirigiendo el lente a la ciudad de México, se enmarca el presente artículo, como un abono inicial a la historia regional y del país, alumbrándonos con aquellos trabajos pioneros, que podemos considerar de historia económica.

Antes de proseguir apuntamos que, en virtud de las varias definiciones que existen sobre el concepto de urbanización, ${ }^{1}$ recogemos la postura de Vries (1987), la cual refiere que es un proceso que se integra de tres dimensiones: urbanización demográfica, urbanización estructural y urbanización cultural; así como la de Morse quien, desde la década de 1970 conminaba a los estudiosos de la urbanización a "combinar las perspectivas demográfica, económica, sociológica, histórico cultural y arquitectónica" (Morse, 1971: 28). Por consiguiente, convenimos que la urbanización es un proceso multidimensional; es decir, que toca aspectos que tienen que ver con la evolución demográfica, económica, política, social, cultural y estructural aunque en el presente trabajo trataremos solamente los ámbitos demográfico y estructural, correspondientes al periodo porfiriano. Fue entonces cuando la minería a gran escala alcanzó su consolidación, en el marco de la política económica del gobierno de Porfirio Díaz orientada a estimular la inversión extrajera para lograr el crecimiento económico del país. En ese contexto, se explica el proceso de urbanización en El Triunfo y Santa Rosalía, con la peculiaridad de que en el primero fue iniciativa del poder público mientras en el segundo quedó en manos de la empresa 




Figura 1. Mapa de las principales poblaciones del Distrito Sur de la Baja California. Elaboración de Pedro Ismael Álvarez García.

minera. De ahí el interés de centrar el estudio en estas dos poblaciones pues el contraste permitirá atisbar similitudes y diferencias.

\section{El Triunfo y Santa Rosalía: sus orígenes y evolución demográfica}

\section{El Triunfo}

El origen de El Triunfo se remonta al año de 1751, cuando Manuel de Ocio, ex-soldado del presidio de Loreto, comenzó a explotar la mina El Triunfo de la Santa Cruz, en las faldas de la sierra de La Laguna, en el extremo sur de la península de California. A partir de 1768 por disposición del visitador José de Gálvez los trabajos mineros, que comprendían también los que se desarrollaban en los reales de Santa Ana y San Antonio desde 1748 y 1756 respectivamente, quedaron bajo la responsabilidad de las autoridades reales. Sin embargo, su escaso éxito, a causa de la escasez de trabajadores, capitales y víveres, hizo que a los pocos años dichas labores pasaran otra vez a manos de los particulares de la región quienes, al igual que sus antecesores, enfrentaron los mismos problemas -además de la falta de azogue. Por consiguiente, la minería siguió distinguiéndose por sus bajos niveles de producción y circunscrita a la riqueza que afloraba en la superficie. No obstante, la colonización civil en esa región, que arrancó con la apertura del real de Santa Ana en 1748, se abría paso en medio del sistema misional que venía funcionando en la península desde $1697^{2}$ (Amao, 1997: 54-98; Trejo, 2002: 198), como lo deja ver la presencia de 305 personas en 1775, cuando en la misión de San Javier, que era la más poblada de éstas, vivían 283 (Amao, 1997: 54-98 y 142), con la precisión de que la primera cifra incluía a toda la población minera de dichos reales.

En 1822, tras la jura de la independencia por las autoridades bajacalifornianas, se dio paso a la vida municipal; surge así la municipalidad de San Antonio, de
2. A partir de 1697 , "los padres jesuitas hicieron de California una provincia misional, es decir, una provincia en la que la misión fue la institución ordenadora de la sociedad, la economía y la organización político-administrativa” (Del Río y Altable, 2000: 65). 
3. AHPLM. Padrón de extranjeros de la municipalidad de San Antonio, 1872, vol. 77 bis, doc. 69 .

4. La fiebre de oro en California inició su declinación en los primeros años de la década de 1850 , cuando el oro que se obtenía de los yacimientos superficiales empezó a agotarse. Sucedió entonces que los estadounidenses promovieron diversas leyes para que sólo ellos pudieran continuar explotando los placeres, de ahí que los nuevos inmigrantes y los extranjeros residentes empezaran a sopesar los relatos que circulaban en la región de que en los territorios del noroeste de México se podrían localizar vetas auríferas parecidas a las de California. Algunos buscadores de oro terminaron convenciéndose de esa idea, seguros de que si en la sierra californiana abundaba dicha riqueza también debía existir en la región montañosa y desértica del noroeste de México. (González, 1993: 349-351; Taylor, 2007: 110-111).

5. AHPLM. Informe sobre el rancho El Triunfo o las Casitas, Santo Tomás, Baja California, 20/4/1871, vol. 104, doc. 044. AHPLM. Oficio de la Secretaría de Gobernación, México, 8/1/1875, vol. 125 bis, doc. 9 .

6. AHPLM. Oficio del agente de negocios de la Compañía Hormiguera Minas de El Triunfo, La Paz, Baja California, 27/1/1868, vol. 94, doc. 09o. AHPLM. Oficio de vecinos de El Triunfo al jefe político del Territorio de la Baja California, El Triunfo, Baja California, 2/5/1870, vol.102, doc. 241. la que El Triunfo pasó a formar parte como una de sus secciones. El desarrollo intermitente de la actividad minera durante la primera mitad del siglo XIX hizo que esa población mantuviera una vida precaria que se prolongó hasta los años sesenta de esa centuria, cuando dicha actividad comenzó a repuntar gracias al arribo de empresas tanto de capital nacional como extranjero.

Si bien fueron los empresarios nacionales los pioneros de la reactivación minera, a la vuelta de los años serían los extranjeros quienes asumirían el control de dicha actividad. Suponemos que la mayoría de estos últimos formaba parte de esos grupos de buscadores de oro que fueron desplazados de California. Tal idea se sustenta en el hecho de que en las solicitudes de denuncios mineros declaraban que representaban los intereses de socios o de empresas que radicaban o se habían originado en San Francisco, California. Otra información que fortalece nuestra hipótesis es que en el padrón de extranjeros de la municipalidad de San Antonio del 1872 aparece que alrededor del $60 \%$ de esa población arribó a la región durante la segunda mitad de la década de 1850, y en el transcurso de la siguiente, ${ }^{3}$ tiempo que coincide con la extinción de la fiebre de oro en California. ${ }^{4}$

De las aproximadamente quince empresas extranjeras existentes entre $1857 \mathrm{y}$ 1877 sobresalió la compañía Hormiguera de Minas de El Triunfo, de capital estadounidense, que se instaló contigua al poblado de El Triunfo en 1864, en una extensión de 1755 hectáreas, ${ }^{5}$ donde se encontraban quince minas; en ese mismo espacio, los directivos de la empresa establecieron una hacienda de beneficio, oficinas administrativas y una tienda de raya (González y Rivas, 2014: 136-144). Se sabe que inició sus operaciones con una inversión de 500 mil pesos (Mason, 2002: 37), suficiente para sentar las bases de la modernización minera en la región, al integrar en el mismo tiempo y lugar los procesos de extracción y beneficio, así como por recurrir a la tecnología en ambas actividades ${ }^{6}$ con lo que se modificaron las formas de producción, trabajo, administración y comercialización. Por consiguiente la empresa requirió de mano de obra permanente y en cantidad suficiente, la que debió conseguir en otras regiones del país y en el extranjero debido a que la población en la municipalidad de San Antonio seguía siendo escasa. En El Triunfo, asiento de la empresa, había apenas 272 habitantes en 1864, de los cuales el 31\% era menor de doce años, situación que comenzó a revertirse a partir de ese año, como se muestra la Gráfica 1.

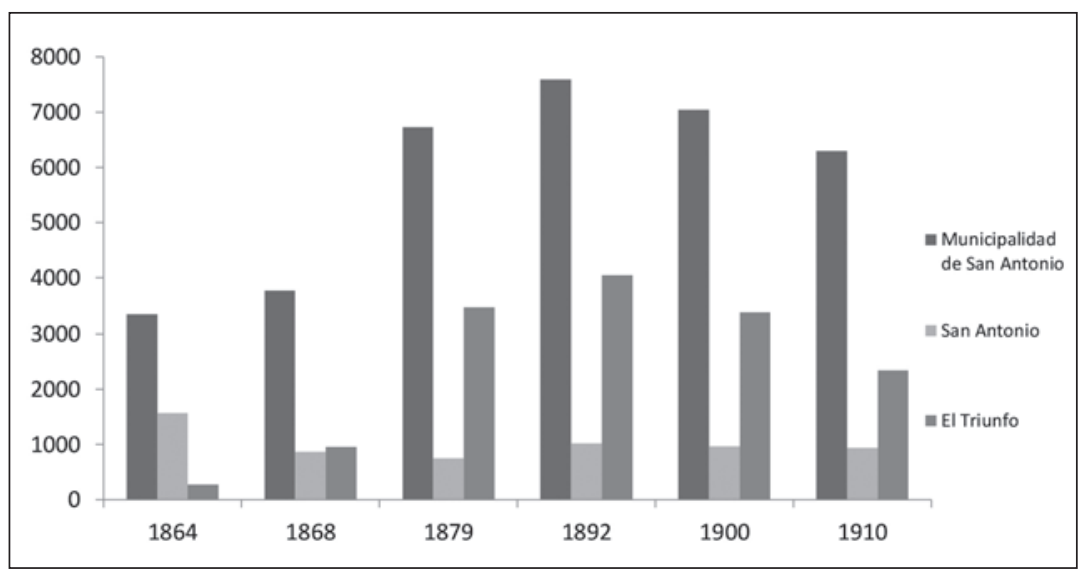

Gráfica 1. Número de habitantes en la municipalidad de San Antonio y en las secciones de San Antonio y El Triunfo (1864-1910). Fuente: AHPLM. Padrones de población de la municipalidad de San Antonio de $1864,1868,1879,1892$ y censos generales de población de 1900 y 1910; vols. 86, 96, 147, 223, 409, 563; docs. $37,808,56,776,937 ;$ exps. $88, \mathrm{~s} / \mathrm{n}, 8$. 
Sin embargo, en 1878 dicha empresa traspasó sus propiedades a la compañía El Progreso, también de capital estadounidense, debido a la incapacidad técnica para extraer el mineral que se encontraba cada vez a mayor profundidad. El Progreso se estableció en condiciones más favorables que su antecesora; además de paz social, concebida como el cimiento para la existencia del régimen y condición para el progreso material del país (Guerra, 1993: 212-219; Krauze, 1987: 27-53), el gobierno de Porfirio Díaz ofreció a los inversionistas extranjeros una infraestructura legal para la explotación de los recursos naturales del país, distinguiéndose la que expidió para el ramo minero, en cuya ley de 1892 se transfirió la propiedad del subsuelo a los particulares (Velasco-Ávila et al.,1988: 350-355; Nava, 1965: 302-306; Sariego et al.,1988: 29).

La compañía El Progreso fue configurando sus fundos mineros mediante diversos denuncios y convenios: en 1878 arrendó a la Compañía Hormiguera las propiedades que ésta poseía en San Antonio, El Triunfo y Cacachilas; en 1890, mediante un convenio con el gobierno federal, formalizó la propiedad de todos los fundos mineros que había denunciado hasta esa fecha y en 1897 logró ampliar por diez años más su contrato. Con base en este convenio, obtuvo la propiedad de las minas y las vetas que se descubrieran en un terreno de aproximadamente 1196 hectáreas y la exención de derechos por la importación de bienes de consumo y capital. ${ }^{7}$

Según un estado de cuentas, del 21 de octubre de 1878 al 30 de diciembre de 1889, la inversión de El Progreso ascendía a cerca de cinco millones de pesos, lo que le permitió la aplicación de nuevas tecnologías en la minería y la metalurgia. En el transcurso de los años ochenta amplió y perfeccionó la planificación de las obras interiores de las vetas, fortificó y colocó nuevos ademes e instaló máquinas de vapor para el desagüe de las minas. ${ }^{8}$ Respecto al método de beneficio, la compañía introdujo el sistema de lixiviación, la incorporación de este método llevó a la empresa a instalar en el pueblo de El Triunfo una hacienda de beneficio en la que montó un torno de 40 mazos, 40 hornos de mano, dos hornos movidos por máquinas de vapor y 20 tinas de lixiviación de 40 cargas cada una. Además, estableció una maestranza para la compostura de la maquinaria, herrería, carpintería y carrocería. ${ }^{9}$ Otra unidad que formó parte de las instalaciones de la compañía fue un ferrocarril de vapor, cuya vía alcanzó una extensión de diez kilómetros. Este medio de transporte conectó las principales minas con la hacienda de beneficio, permitiendo trasladar a ésta un considerable volumen de mineral. ${ }^{10}$

Por los gastos que erogó la empresa entre 1893 y 1896 se advierte que no dejó de incrementar sus inversiones, ni de mejorar tecnológicamente sus procedimientos de extracción y beneficio del mineral. ${ }^{11}$ En 1898 introdujo el método de cianuración para lo cual construyó cinco tanques de madera con capacidad de 400 toneladas cada uno, en los que se depositaban los minerales pulverizados provenientes de la hacienda, y tres tanques más pequeños para almacenar la solución que se empleaba en el beneficio. Los minerales eran conducidos al nuevo establecimiento en cubetas de fierro que resbalaban a lo largo de un cable de acero accionado por medio de un motor de vapor. ${ }^{12}$ Con esta innovación, El Progreso estuvo a tono con empresas de otras regiones del país -Guanajuato, Chihuahua, Durango, Zacatecas y Sonora-, que igualmente fueron transformando sus haciendas para el uso del procedimiento de cianuración (Velasco-Ávila et al., 1988: 276-278).
7. AHPLM. Informe del jefe político al secretario de Fomento, La Paz, Baja California, 14/4/189o, vol. 211, exp. 9. AHPLM. Contrato celebrado entre el gobierno federal y la compañía minera El Progreso, México, 2/3/1897, vol. 269, exp. 8.

8. AHPLM. Informe del jefe político sobre su visita al mineral de El Triunfo, La Paz, Baja California, 12/5/189o, vol. 208, exp. 13.

9. AHPLM. Informe del jefe político sobre su visita al mineral de El Triunfo, La Paz, Baja California, 12/5/189o, vol. 208, exp. 13 .

10. AHPLM. Informe del jefe político sobre su visita al mineral de El Triunfo, La Paz, Baja California, 12/5/189o, vol. 208, exp. 13 .

11. BAGN). Memoria de Fomento 1892-1896.

12. AHPLM. Autorización para establecer una planta de cianuro, El Triunfo, Baja California, 7/4/1898, vol. 303 , exp. 87 . 
13. AHPLM. Teléfonos urbanos particulares, El Triunfo, Baja California, 21/5/1902, vol. 331, exp. 184.

14. AHPLM. Informe del representante de la Cía. Hormiguera al jefe político del Territorio de la Baja California, La Paz, Baja California, 21/8/1876, vol. 134 bis132, doc. 142, exp. 1. AHPLM. Informe que el ingeniero en minas Filiberto Alarcón, La Paz, Baja California, 1915, vol. 633, exp. 20.

15. A partir del 1 de enero de 1888 el Territorio de la Baja California quedó dividido en dos distritos políticoadministrativos: el Distrito Sur y el Distrito Norte.

16. AHPLM. Padrón de la municipalidad de San Antonio de 1892, vol. 223, exp. 88.

17. Padrón de la municipalidad de San Antonio de 1864, AHPLM, vol. 86 , doc. 37.

18. AHPLM. Censo General de Población de 1900, vol. 409, exp. s/n, doc. 776. AHPLM. Censo General de Población de 1910, vol. 563, exp. 8, doc. 937.
El teléfono fue un medio más de comunicación que introdujo la empresa hacia 1902; su línea, de ocho kilómetros de extensión, comunicó a la hacienda de beneficio con las principales minas. ${ }^{13}$

La introducción de esas innovaciones tecnológicas trasformó en definitiva la estructura productiva, pues se pasó de la producción en pequeña escala a la obtención de miles de toneladas por año. Por ejemplo, en los años setenta se tienen noticias de que la extracción de mineral anual fue en promedio de 500 toneladas, mientras en los ochenta ascendió a 120 mil, con un rendimiento de 148 toneladas de plata fina. ${ }^{14}$

Esta nueva modernización de la estructura productiva requirió de un número importante de trabajadores que se encargara de las diversas etapas del proceso. Por ejemplo, entre 1879 y 1889, la compañía El Progreso empleó 9036 personas, un promedio anual de 821. En la siguiente década, la ocupación promedio al año fue de 963 trabajadores: 704 en las minas y 259 en la hacienda, un incremento de 17\% con respecto a los años ochenta (Rivas, 2000: 56).

En ese contexto se explica el disparo demográfico que se registró en la municipalidad de San Antonio tras el establecimiento de la compañía El Progreso, siendo en El Triunfo donde se registró el mayor crecimiento poblacional (Gráfica 1). De 272 habitantes existentes en 1864 la cifra se elevó a 4051 en 1892, un incremento de casi 15 veces. De este total de habitantes, sólo el 39\% había nacido en El Triunfo, el resto estaba compuesto por migrantes, distribuidos así: $46.2 \%$ procedía de las otras poblaciones del Distrito Sur de la Baja California, ${ }^{15}$ principalmente de San Antonio, Todos Santos, La Paz, San José del Cabo y Santiago; el 13.3\% llegó del macizo continental, sobre todo de Sinaloa y Sonora; y el 1.3\% estaba compuesto de extranjeros, distinguiéndose los europeos y los estadounidenses. ${ }^{16}$

El cambio en la población no fue meramente cuantitativo, los padrones de 1864, 1868, 1879, 1892 y los censos de 1900 y 1910 dejan ver que hubo también una mudanza cualitativa. Una primera expresión de ello es el carácter estratificado que fue adquiriendo la sociedad triunfeña, como se anticipa ya en el censo de 1857, en el que se distinguen operarios, mineros y criadores, aunque sin mencionar la fortuna o ingresos de éstos. Más luz al respecto da el censo de 1864 pues consigna el caudal que poseían algunos habitantes, lo que nos permite inferir que en la cúspide social se encontraba un puñado de criadores cuya fortuna iba de mil quinientos pesos a doce mil pesos; un sector medio, conformado por criadores, comerciantes y mineros, con un peculio de cien a mil pesos, en el que incluimos al preceptor y a los que se dedicaban a algún oficio -como de zapatero, carpintero albañil y herrero-; la parte baja de la pirámide social estaba constituida por un poco más de una veintena de operarios. ${ }^{17}$

El padrón de 1879 abona a esta idea de la estratificación social pues ahí viene asentado el servicio de criados o sirvientes -22, entre hombres y mujeres- al que recurrieron seguramente las familias pudientes del pueblo. Un servicio que conforme transcurrió el tiempo fue más demandado, como se atisba en los censos generales de población de 1900 y 1910 con la advertencia de que ambos corresponden a toda la municipalidad. Sin embargo, el que en El Triunfo se concentrara principalmente la actividad minera nos lleva a presumir que ahí existió la mayor demanda de ese servicio y detonó la aparición de otro, como fue el de las lavanderas. De dieciséis lavanderas registradas en 1900 su número se elevó a 81 en 1910; en cuanto a los criados o sirvientes, de 53 -32 hombres y 21 mujeres- anotados en 1900 se pasó a 80 en $1910-23$ hombres y 57 mujeres. ${ }^{18}$ 
Estas mismas fuentes nos permiten ver la aparición de otros actores sociales: profesionistas -abogados, médicos e ingenieros-, funcionarios de la administración pública y empleados públicos y privados, como consecuencia del mismo auge minero; el cual, a su vez, provocó una reorganización del aparato político administrativo en la municipalidad. La cabecera municipal se trasladó del pueblo de San Antonio al de El Triunfo, ahí mismo se relevó el juzgado de Paz por uno Menor, ${ }^{19}$ se estableció una agencia de policía y se asentó una subprefectura con jurisdicción en las municipalidades de San Antonio y Todos Santos (González y Rivas, 2013: 9-10). Así pues, la estratificación social adquirió un nuevo rostro: al grupo minoritario de criadores, comerciantes y mineros se sumaron los agricultores y los encargados del poder público; igualmente el sector medio fue robustecido con los profesionistas y empleados públicos y privados; mientras el sector más empobrecido vio crecer su base con la incorporación de un mayor número de operarios, además de peones, lavanderas y criados o sirvientes.

La división del trabajo es otra lectura que se deriva de las fuentes que venimos refiriendo, lo que evidencia una sociedad más compleja. A las actividades primarias -agricultura, ganadería y minería- se agregaron los oficios y servicios. De los oficios hay evidencias de que en 1857 sólo existía el de sastre y era ejercido por una única persona; esto comenzó a cambiar a partir de 1864, adquiriendo su mayor expresión entre 1892 y 1910 cuando en promedio al año se ocuparon 143 personas en dieciséis labores de ese tipo (Gráfica 2), sobresaliendo aquellas que tenían que ver con los requerimientos de la actividad minera y la construcción -carpinteros, albañiles y herreros-, la elaboración de bienes de consumo -costureras, sastres, zapateros, talabarteros y panaderos- y actividades artísticas -músicos.

Respecto a los servicios, éstos corrieron la misma suerte que los oficios pero con el matiz de que su punto culminante ocurrió entre 1900 y 1910, además de que el número de personas que se ocuparon en ellos fue de casi 250 en promedio al año, un 75\% más del que se dedicaba a los oficios (Gráfica 2). El rubro mercantil destacó como el más dinámico, sin desmerecer la evolución que tuvo el de empleados y funcionarios públicos como consecuencia de la reorganización del aparato político-administrativo y la atención a la instrucción pública; igual de notorio fue la necesidad de preceptores, lavanderas y criadas o sirvientes.

Por consiguiente el cambio cuantitativo y cualitativo de los oficios y servicios, que respondió al impacto demográfico y a la estratificación social que trajo la actividad minera, nos permite avistar que, a partir de la década de 1890, El Triunfo fue distinguiéndose por su fisonomía urbana. Su espacio, trazado en forma de damero, se vio sembrado de una arquitectura más robusta, de carácter privado y público; de un aparato político-administrativo, judicial y policial; de servicios para el abasto de bienes de consumo, así como para la instrucción, salud, seguridad, limpieza, ornato y culto. Ello devino en nuevos hábitos y costumbres; es decir, un modo de vida propio de una comunidad urbana.
19. Las atribuciones de los jueces de paz consistían en castigar los delitos leves -siempre que la pena no pasara de treinta días de arresto o 50 pesos de multa-, practicar las primeras diligencias en averiguación de los demás delitos, conocer de los juicios civiles cuyo monto no exceda de 50 pesos y evacuar las diligencias que les encomendaran los jueces de primera instancia o menores. A los jueces menores correspondía conocer en materia civil sobre los negocios cuya cuantía no excediera los 500 pesos y en materia penal los delitos en que la pena no pasara de dos meses de arresto o 200 pesos de multa, fuera conjuntiva o alternativa la pena, y los robos simples cuya cuantía no excediera los 50 pesos. AHPLM. El Distrito Sur, La Paz, Baja California, 15/6/1907, vol. 476 , exp. 204. 


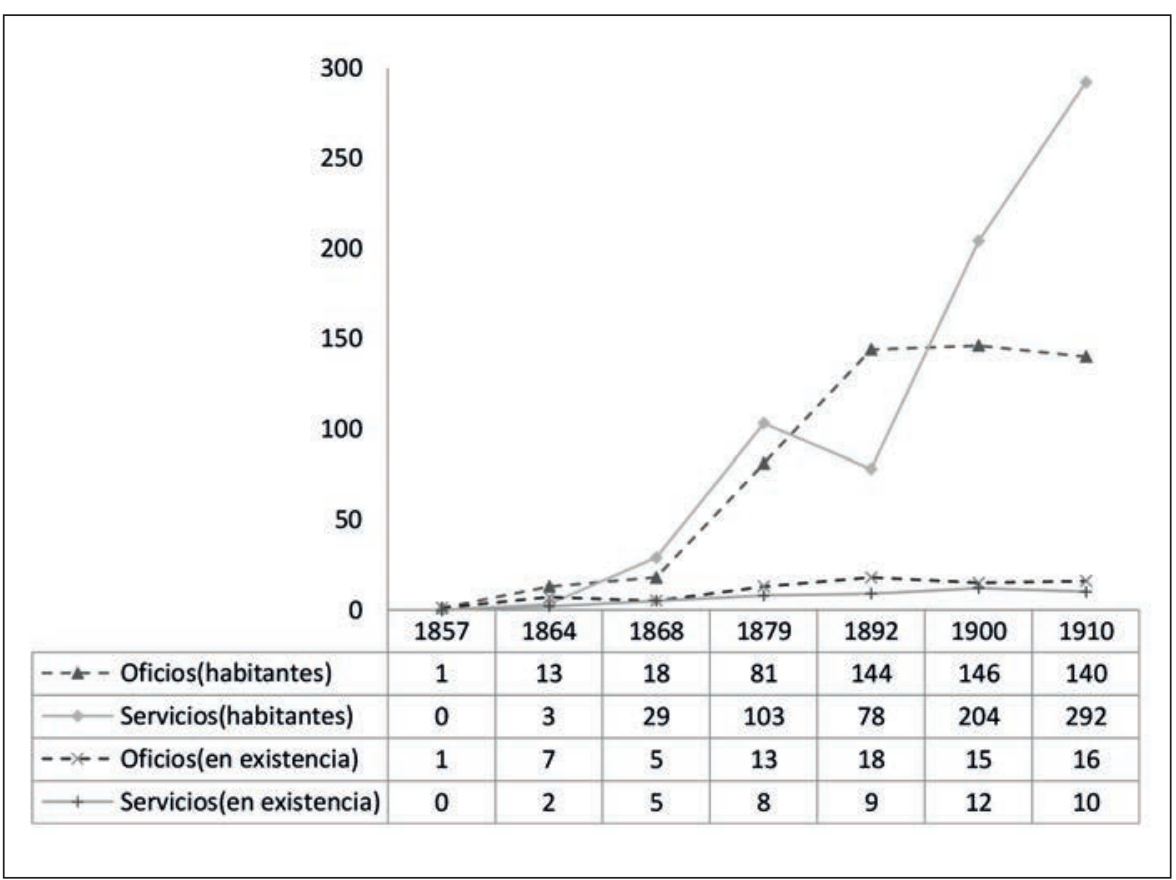

Gráfica 2. Oficios y servicios en El Triunfo (1857-1910). Fuente: AHPLM. Padrones de población de la municipalidad de San Antonio de 1857, 1864, 1868,1879, 1892 y censos generales de población de 1900 y 1910; vols. 68 bis, 86, 96, 147, 223, 409, 563; docs. 180, 37, 808, 56, 776, 937; exps. 88, s/n, 8 .

\section{Santa Rosalía}

Santa Rosalía fue un pueblo que quedó incluido en la municipalidad de Mulegé, localizada en la parte norte de lo que hoy es el estado de Baja California Sur. Dicho pueblo comenzó a formarse en el verano de 1885, como basamento para la extracción y beneficio del cobre por parte de la compañía francesa El Boleo, la cual había recibido del gobierno federal una propiedad de veinte mil hectáreas para el desarrollo de esa actividad cuprífera, con el compromiso de impulsar la colonización en esa región hasta entonces prácticamente despoblada. Aunque la riqueza cuprífera había sido descubierta en 1868, su explotación venía haciéndose por pequeñas empresas de lugareños y extranjeros residentes en el puerto sonorense de Guaymas (González, 1985: 19-22; Romero, 1991: 49-55), lo que la distinguió por su atraso técnico y el uso primordial de la fuerza humana:

El primer trabajo se llevó a cabo con material rudimentario y sin ningún método; la extracción del metal se hacía por galerías inclinadas que llegaban hasta las capas de mineralización; los obreros, casi todos indios yaquis traídos de Sonora, extraían el mineral en sacos de cuero o tanates que subían al hombro.

20. AGN. Historia del mineral de Santa Rosalía Dirección General de Gobierno, 12/4/1926, vol. 16, exp. 14 .
En el patio de la mina se seleccionaba el mineral separando el más pobre y se recogían sólo las muestras que tenían una ley de 20 a 25\% de cobre. ${ }^{20}$

Frente a esas circunstancias, no pasó mucho tiempo para que poderosos inversionistas extranjeros dirigieran su mirada hacia esa riqueza cuprífera que guardaba el subsuelo mulegino, cuya importancia comenzó a ser estratégica para el desarrollo de las comunicaciones y la industria eléctrica -y aunado a la nueva infraestructura legal que en el ramo minero ofreció el gobierno de Porfirio Díaz. En ese contexto la Casa Rothschild y la Mirabeau Banking Corporation de París, Francia, formaron la compañía El Boleo el 16 de mayo de 1885, con un 
capital inicial de doce millones de francos. Las condiciones legales bajo las cuales operó la compañía se fijaron en principio en un contrato que la empresa suscribió con el gobierno federal el 7 de julio de $1885 .{ }^{21}$ La concesión a la compañía abarcó once fundos mineros en una superficie de veinte mil hectáreas. La Federación conservó la propiedad de la zona marítima, comprendida desde la línea marcada por las aguas en la marea alta hasta veinte metros de la costa, tierra adentro, permitiéndole a la empresa utilizar dicha franja para construir muelles, diques, almacenes, ferrocarriles y fundiciones.

Por el mismo contrato de origen, la empresa quedó exenta del pago de toda clase de impuestos federales, locales, de importación y de exportación por un lapso de veinte años, además el gobierno federal se comprometió a construir, en un término de tres meses, un puerto de altura y cabotaje en lo que se conocía como la ensenada de Santa Rosalía. Por su parte, la empresa francesa se obligaba a fundar en el plazo de un año una colonia con un mínimo de dieciséis familias extranjeras y 50 mexicanas, a proporcionar el servicio de un vapor de cuanto menos 50 toneladas para cubrir la ruta Santa Rosalía-Guaymas -con escala en el puerto de Mulegé a la ida y al regreso-, a construir todos los edificios necesarios para el establecimiento de las oficinas y almacenes de la aduana marítima y a poner en funcionamiento una hacienda para el beneficio de los minerales que se extrajeran. ${ }^{22}$

A diferencia de la compañía El Progreso, El Boleo se estableció en un espacio prácticamente despoblado y con antecedentes mineros que apenas rebasaban una década. En 1878, la municipalidad de Mulegé tenía 1530 habitantes, cifra que la ubicaba atrás de todas las municipalidades que constituían el Territorio de la Baja California. En su cabecera, que era el pueblo de Mulegé, vivían alrededor de 600 personas; un número parecido habitaba en el pueblo de San Ignacio y el resto se distribuía en los diferentes ranchos (González, 2000: 85)

Tal circunstancia llevó a la compañía francesa no sólo a levantar la infraestructura necesaria para la extracción y beneficio del mineral sino también a construir un pueblo dentro de los límites de su propiedad. Como cualquier otra sección municipal, a Santa Rosalía se le dotó de una estructura político-administrativa conformada por una alcaldía, una oficina recaudadora, un juzgado de Paz y un servicio de policía y cárcel sujeta al cuerpo de ediles que residía en el poblado de Mulegé, cabecera de la jurisdicción (González, 2016: 39-76).

Otro matiz respecto a El Triunfo, es que Santa Rosalía, desde su nacimiento, adquirió un perfil urbano como se infiere de los datos cuantitativos de la población y de la estructura ocupacional. Respecto al número de habitantes, de 379 que había en enero de 1886 se pasó a 9.227 en 1910, como se observa en la Gráfica 3.

Aunque sólo contamos con cuatro datos sobre el total de habitantes en la municipalidad mulegina, estos dejan ver que Santa Rosalía concentró el 60 \% de las personas que vivían en esa jurisdicción, con la peculiaridad de que casi la totalidad provenía de los estados de Sinaloa, Sonora, Jalisco, Colima y el Territorio de Tepic, pues sólo así la empresa solventaba su demanda de operarios. Al adentrarnos en los datos demográficos, específicamente los correspondientes a un padrón que tenemos de1904, más otros documentos donde se da cuenta sobre quiénes eran los principales comerciantes del lugar, los tipos de casas, las categorías y los salarios de los trabajadores de la empresa mine$\mathrm{ra}$, el retrato que se atisba es el de una sociedad marcadamente estratificada. En primer término podemos inferir que estaban los directivos de la empresa
21. AHPLM. Contrato que celebró el Gobierno Federal con Manuel Tinoco y Carlos Eisenmann, México, 7/7/1885, vol. 214, exp. 2.

22. AHPLM. Contrato que celebró el Gobierno Federal con Manuel Tinoco y Carlos Eisenmann, México, 7/7/1885, vol. 214, exp. 2. 


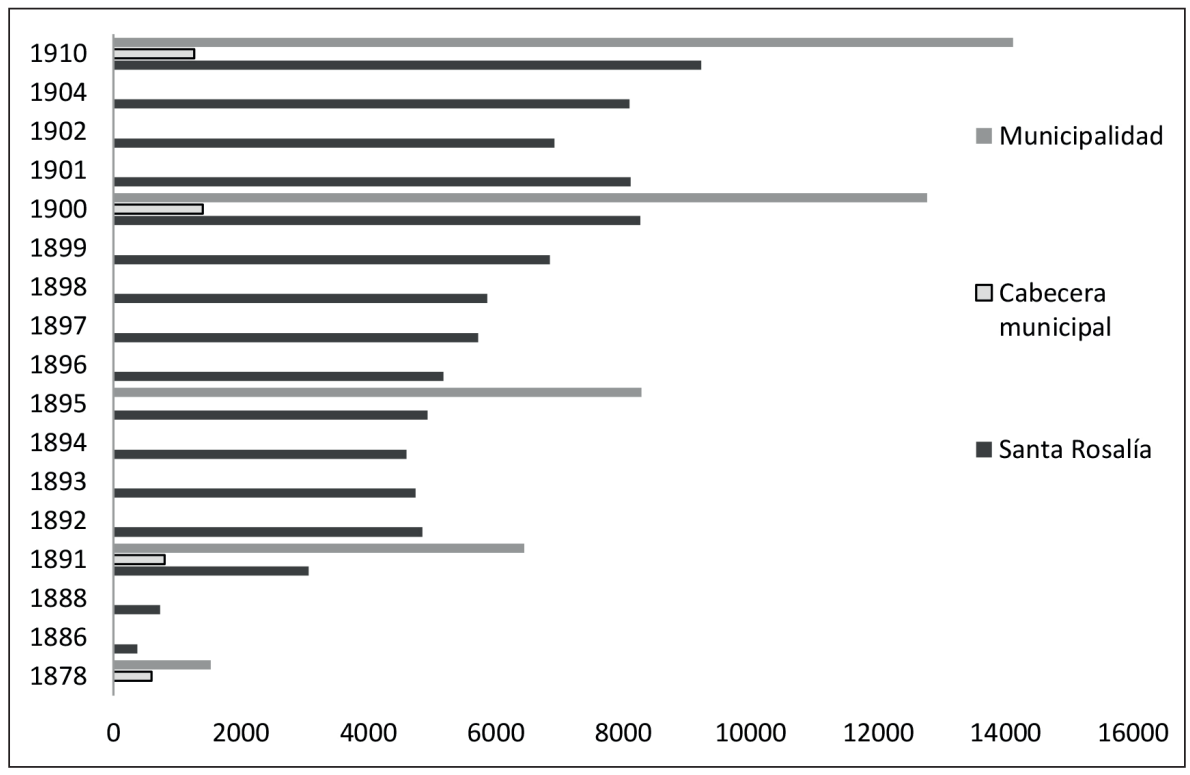

Gráfica 3. Número de habitantes en Santa Rosalía, cabecera municipal y municipalidad (1878-1910). Fuente: (González, 2106: 77-78). AHPLM. Padrón de habitantes de Santa Rosalía de 1904, vol. 369, doc. 162, exp. 39. Censos de población generales de1895, 1900 y 1910; vols. 259, 409, 563; docs. 4, 776, 937; exp. s/n, 8.

23. AHPLM. Padrón de habitantes de Santa Rosalía de 1904, vol. 369, doc. 162 , exp. 39 .

24. AHPLM. Censo del mineral de Santa Rosalía al 31 de diciembre de 1890 , leg. 27 , doc. 24. minera, algunos comerciantes, funcionarios públicos y empleados de la misma compañía, entre ellos los médicos; en el estrato medio, los empleados que se ocupaban en los diversos oficios y servicios, en los que predominaban los contadores, maquinistas, carpinteros, electricistas, capitanes, herreros, capataces, farmacéuticos y profesores; y en la base de esa pirámide social todas aquellas personas dedicadas a la extracción del mineral, que en promedio al año era de 1600 -además de criadas, lavanderas, cocineras y prostitutas. Si bien el padrón de 1904 es bastante detallado en cuanto a la división del trabajo, tiene partes ilegibles que nos impidieron identificar de manera precisa su composición cuantitativa; no obstante pudimos reconocer que, además de la categoría de operarios existían alrededor de treinta oficios, de estos veintiuno tenían que ver con la actividad minera y la construcción y el resto respondía a las necesidades de consumo y distracción de los pobladores; de los servicios, distinguimos dieciséis cuya relación respondía a labores contables, mercantiles, salud, instrucción, orden y domésticas, entre otras; ${ }^{23}$ algunos de éstos revelan la exigencia de ciertos conocimientos técnicos lo que explica la presencia de personal extranjero. Por ejemplo, en 1890 se reportan 101 extranjeros, casi todos europeos en su mayoría de franceses (53\%), pero también italianos, quienes representaban un $38 \%$ del total de esa fuerza de trabajo. ${ }^{24}$

Estamos, pues, frente a un cierto grado de afinamiento en algunos sectores observable en la escuela, la vivienda, en las formas de recreo, alimentación, vestido y en la distinción del espacio.

Este nuevo escenario de vivencia colectiva, que Ugo Pipitone concibe como "un cuerpo social complejo, mezcla de distintos intereses y visiones que conviven en una unidad en casi permanente conflicto consigo misma" (Pipitone, 2003: 21), requirió de normas que regularan esa "ausencia de reposo" (Pipitone, 2003: 8). Tanto en El Triunfo como en Santa Rosalía la convivencia social quedó sujeta a una serie de reglamentos oficiales, entre ellos el de propios y arbitrios, solares, prostitución, policía, panteones, cárcel, rastro y bando de policía y buen gobierno; con la particularidad de que en Santa Rosalía la empresa minera El 
Boleo, como dueña del espacio y de los bienes inmuebles, agregó a los ordenamientos municipales los propios.

Cabe decir que en el Bando de Policía y Buen Gobierno, vigente a partir de 1895, podemos colegir la forma en que era percibido lo urbano por parte de la élite política y los medios que consideraba pertinentes para enfrentar los problemas derivados de ello. Por ejemplo, en dicha norma quedaron regulados el comportamiento público, la portación de armas, las diversiones, la prostitución, las inhumaciones, la limpieza de las calles, las plazas y los mercados, la construcción de viviendas y comunes, la presencia y tránsito de animales, la matanza de reses y el acarreo de la carne, entre otros; asimismo, fueron definidas el tipo de faltas y las sanciones. ${ }^{25}$

\section{El diseño espacial}

Además de un cambio demográfico y ocupacional, el desarrollo minero trajo también una transformación en el aspecto físico de El Triunfo y Santa Rosalía; es decir, en el diseño de su espacio. En el caso de El Triunfo esa tarea quedó en manos del poder público, el cual hizo suya la traza en forma de damero (Figura 2), característica de las formaciones urbanas coloniales donde el eje central del dibujo era la plaza y a su alrededor estaban las sedes del poder civil y del eclesiástico. La aglomeración de habitantes llevó a la distinción del espacio: había solares de primera y segunda clases, cuyo valor era de dos y un centavo el metro cuadrado, respectivamente; las nuevas edificaciones, que se levantaron en la parte céntrica, se construyeron, en su mayoría, de ladrillo y de manera ordenada, pues el artículo 43 del Bando de Policía y Buen Gobierno rezaba lo siguiente:

No se permite en lo sucesivo que en las calles céntricas de la población, dentro del radio alumbrado, se construyan o reconstruyan casas o jacales con techo de paja, palma, zacate $u$ otro material de esa naturaleza, bajo la pena de ser obligados los propietarios a destruirlos a su costa y a satisfacer una multa de cinco a veinticinco pesos. ${ }^{26}$

El trazo arquitectónico cambió aún más con la construcción de la casa municipal, la cárcel, el mercado, el jardín público, la escuela, el teatro y la biblioteca; así como con la introducción de los servicios de alumbrado, agua y limpieza; además de dotar a las calles de una nomenclatura en la que aparecieron nombres de personajes nacionales, locales y extranjeros. Complementaron este retrato las principales instalaciones de la compañía El Progreso: la planta de beneficio con sus altas chimeneas de ladrillo, el edificio de las oficinas administrativas, donde se encontraba empotrado el único reloj público del lugar, y un amplio galerón que se utilizó para dar albergue, en un principio, a la iglesia del pueblo (Figura 3).

Respecto a Santa Rosalía, se fundó en una zona de mesetas y cañada por lo que su traza se distinguió por ser un dibujo irregular (Figura 4) que facilitó a la empresa concretar ese modelo segregacionista en la organización del espacio que imperaba en el mundo occidental como impronta del desarrollo capitalista. Así pues, en la cañada se estableció el pueblo, llamado de La Playa u Hondonada México, asiento de los operarios y los empleados inferiores de la empresa y el gobierno; en la meseta que estaba al norte del pueblo de la Playa, llamada Mesa Francia, se ubicaron los directivos y empleados franceses; y en
25. AHPLM. Bando de policía y buen gobierno aprobado el 25 de diciembre de 1894 , vol. 256, doc. 22, exp. $\mathrm{s} / \mathrm{n}$.

26. AHPLM. Bando de policía y buen gobierno aprobado el 25 de diciembre de 1894 , vol. 256 , doc. 22 , exp. $s / n$. 


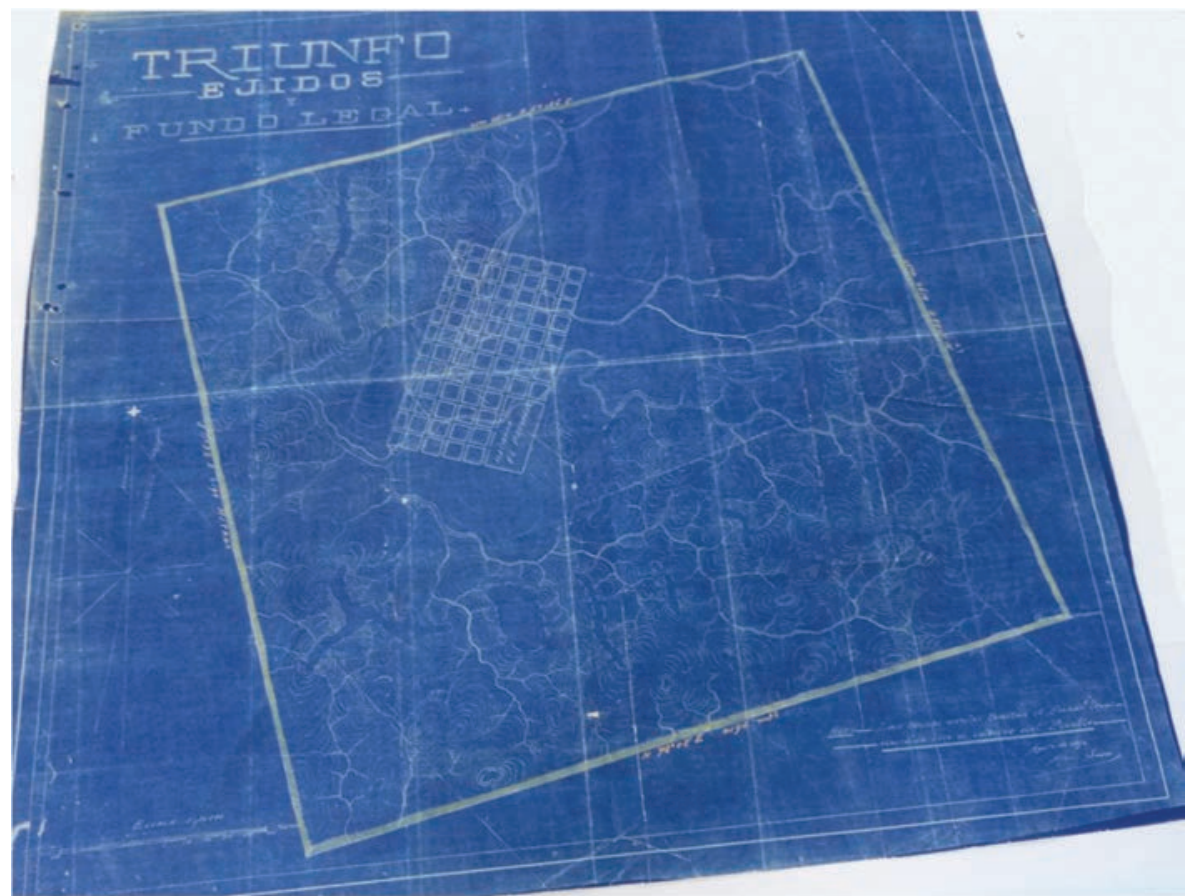

Figura 2. Plano de El Triunfo (AHPLM).

la que estaba al sur, conocida como la Mesa México, residían los empleados superiores del gobierno (González, 2000: 50-85; Kortheuer, 2001: 228-232).

Todas las viviendas fueron construidas de madera pero había distinción entre ellas. Las del pueblo de la Playa eran de treinta metros cuadrados, con un pequeño cuarto para baño, un estrecho corredor para cocina y un lavadero a la intemperie, por las que la empresa cobraba un peso mensual por la renta $y$, a partir de 1904, agregó dos pesos diez centavos por consumo eléctrico. Las

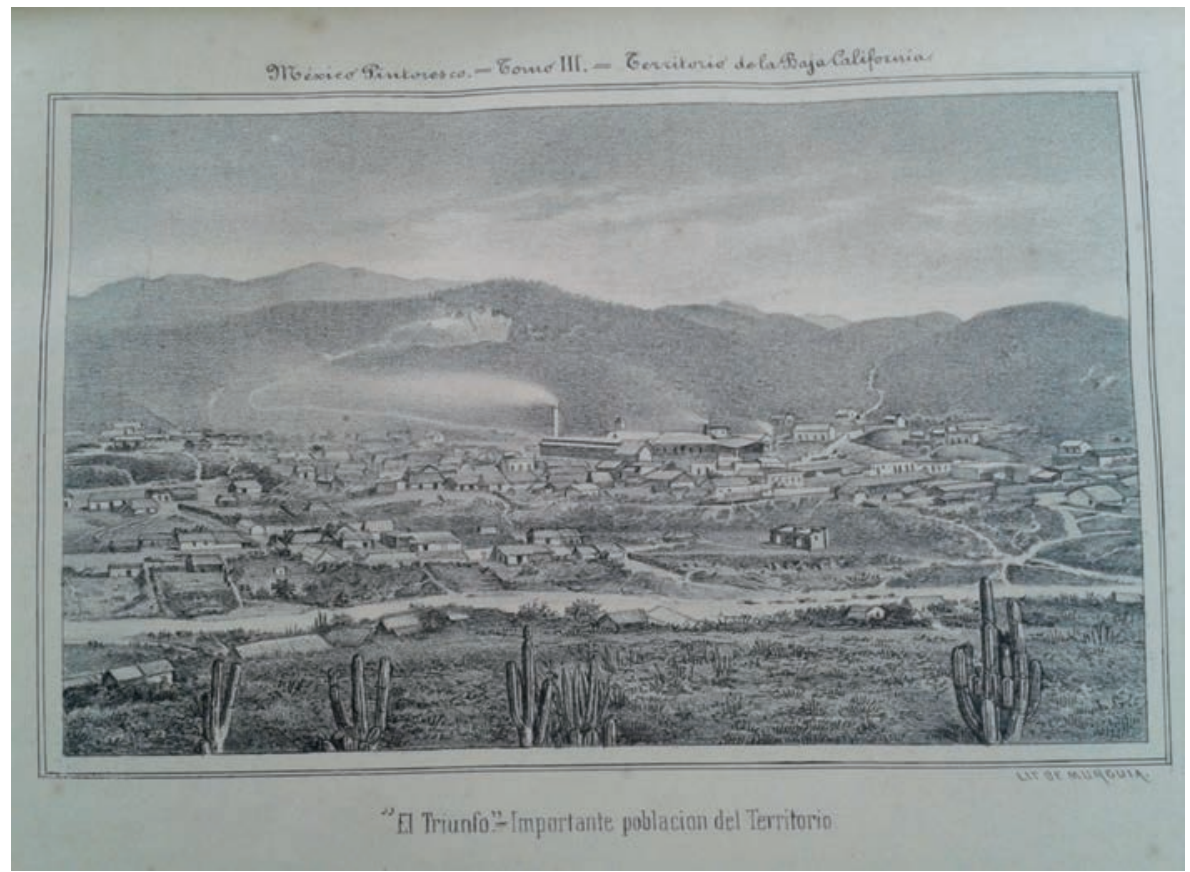

Figura 3. Imagen de El Triunfo (Rivera, 1883). 
de la Mesa Francia contrastaban con aquellas por su amplitud, privacidad, ventilación y servicios; eran cuadradas con techos en forma de pabellón y corredores por todos los lados, desde donde sus moradores podían admirar el hermoso paisaje del mar Bermejo; sus dimensiones eran de un poco más de 70 metros cuadrados, incluían de cuatro a seis aposentos, cocina y baño separados (Figura 5). Las de la Mesa México se caracterizaban también por ser independientes unas de otras, con baño y divisiones en su interior, aunque más pequeñas que las de la meseta del norte. ${ }^{27}$
27. AGN. Informe del ingeniero Alfredo Savín al tesorero general del Distrito Sur de la Baja California, 14/4/1926, Dirección General de Gobierno, vol. 16, exp. 14

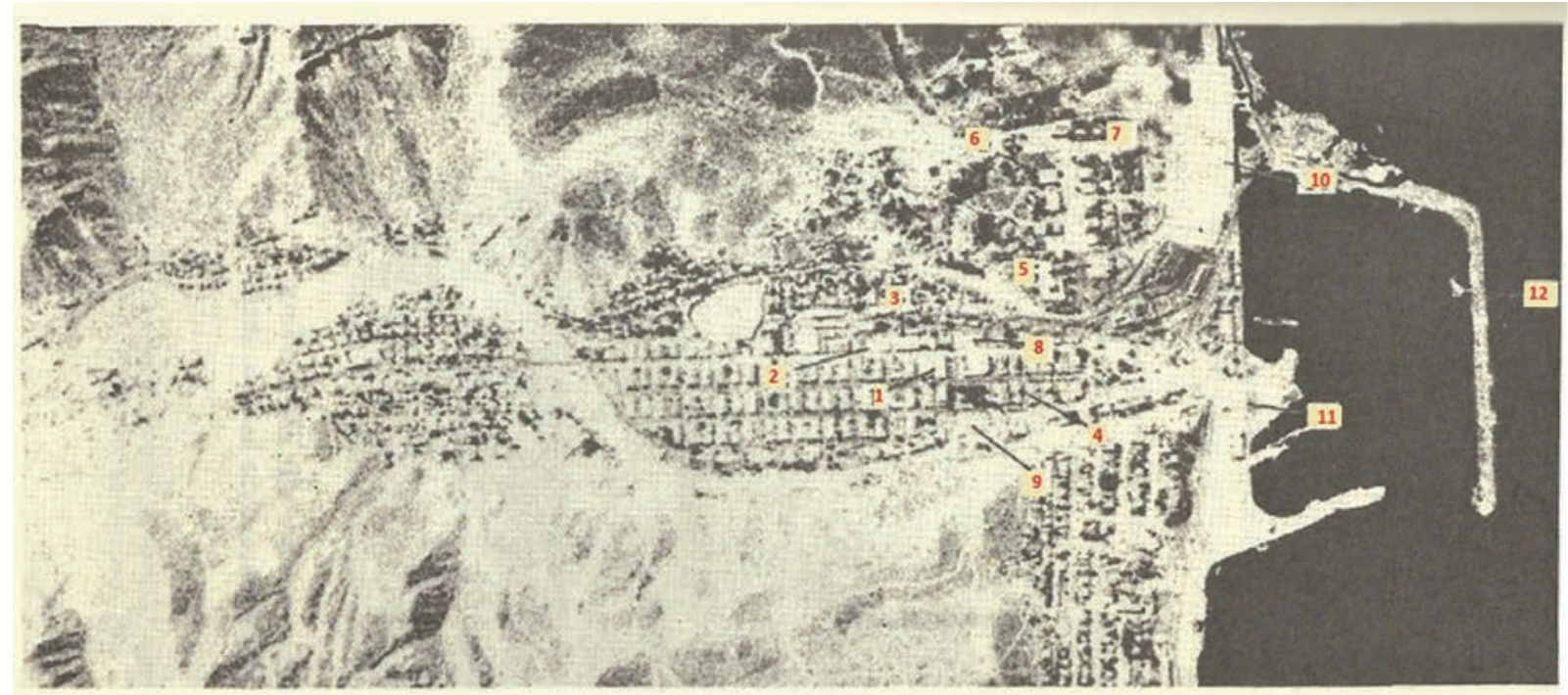

1.- Hotel Central

2.- Panadería El Boleo

3.- Tienda El Boleo

4.- Administración de Correos

5.- Oficinas generales de El Boleo

6.- Depósito de agua

\section{7.- Hotel Francés \\ 8.- Templo de Santa Bárbara \\ 9.- Escuela \\ 10.- Fundición \\ 11.- Edificio de aduana (demolido en 1969) \\ 12.- Puerto}

Figura 4. Plano de Santa Rosalía (Sistema de Información Geográfica de la Universidad Autónoma de Baja California Sur).

Además de las casas para los trabajadores y las oficinas públicas -Aduana Marítima y Capitanía de Puerto-, en el pueblo de la Playa se levantaron la tienda de raya, la escuela, la iglesia, el hotel Central, el teatro, la panadería, la cantina, la cárcel, el prostíbulo, el dispensario médico, la plazuela y el kiosco; en tanto en la Mesa Francia también se establecieron el edificio de la dirección de la empresa, que tenía empotrado un reloj de cuatro carátulas luminosas, el hospital y el hotel Francés; en su falda oriental, hasta terminar en el malecón, se edificaron la hacienda de beneficio, los talleres de reparación de maquinaria, el taller mecánico de carpintería y los patios donde se depositaban las refacciones y las piezas inutilizadas. ${ }^{28}$ Asimismo, esta estructura urbana se vio aderezada con los servicios de alumbrado eléctrico, agua, salud, abasto e instrucción, amén de que las calles fueron identificadas con una nomenclatura definida por números cardinales, en lugar de asignarles un nombre de la lista de héroes nacionales o locales.
28. AGN. Informe del ingeniero Alfredo Savín al tesorero general del Distrito Sur de la Baja California, Dirección General de Gobierno, 14/4/1926, vol. 16, exp. 14 . 


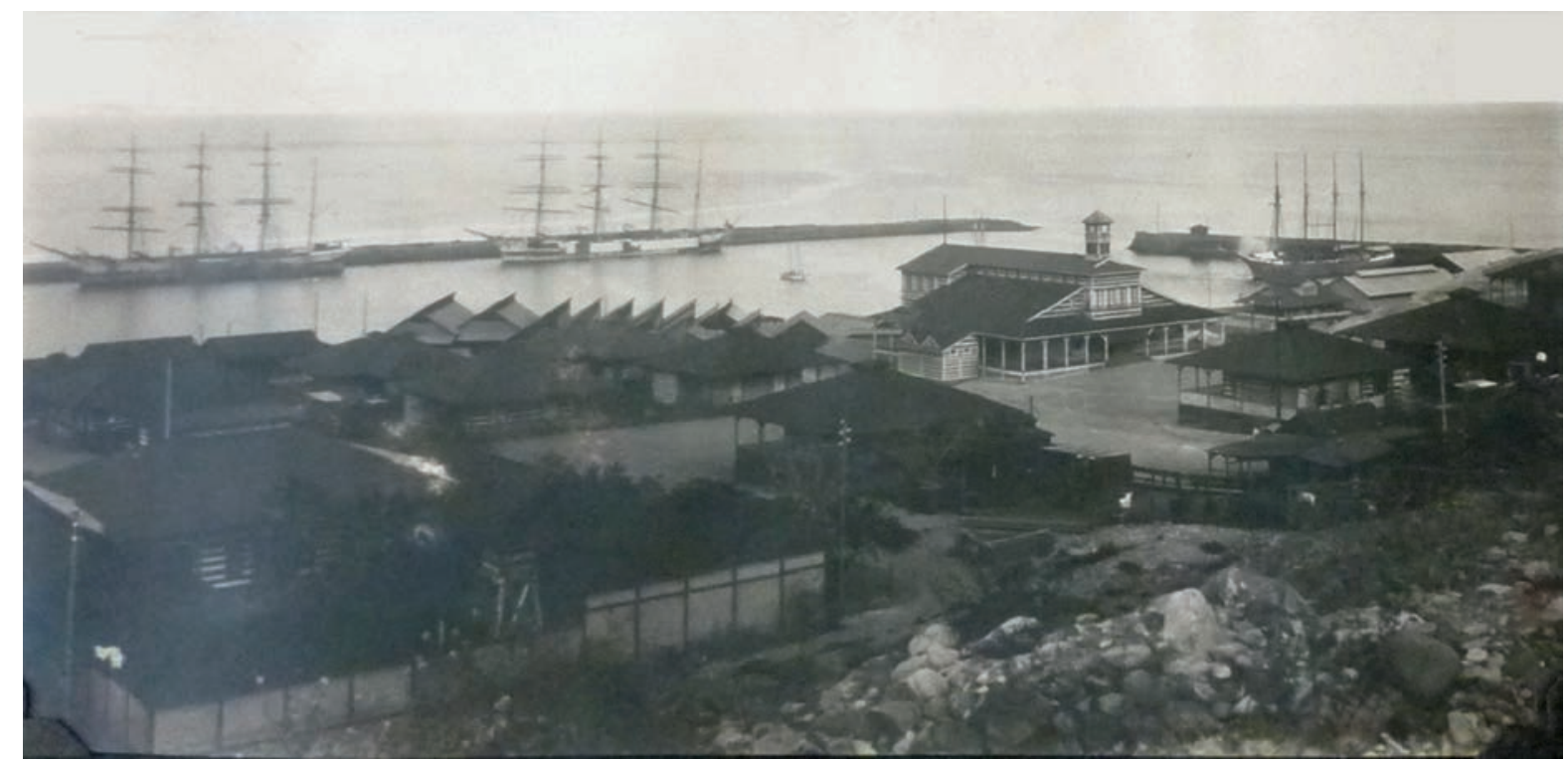

Figura 5. Imagen de La Mesa Francia (AHPLM).

\section{Consideraciones finales}

Durante la época porfiriana cambió la fisonomía de la media península, que hasta entonces se había caracterizado por su pobreza demográfica y económica, atribuible a su geografía árida y periférica. Esta transformación descansó en el desarrollo de la actividad minera que durante ese periodo se distinguió en el país por la explotación a gran escala de antiguos y nuevos yacimientos de minerales preciosos e industriales. A partir de entonces, aquella lejana región del noroeste comenzó a cobrar importancia en el país, sobre todo, gracias a que su subsuelo rico en cobre, que para fines del siglo XIX adquirió una gran demanda en el mercado mundial. En ese contexto, la península de la Baja California, Sonora y Sinaloa se convirtieron en asientos de importantes empresas extranjeras que llegaron a explotar la riqueza argentífera y cuprífera, entre ellas se destacaron las compañías The Progreso Mining Company y Compagnie du Boleo, en Baja California; Tajo Mining, en Sinaloa; Cananea Consolidated Copper Company y Moctezuma Copper Company, en Sonora. Por consiguiente, sostenemos que la minería fue el pivote sobre el que giró la mudanza del paisaje del noroeste, sembrado de nuevos pueblos con un modelo de urbanización peculiar, del crecimiento demográfico y económico de otros y del establecimiento de una infraestructura de vías de comunicación y transporte.

El Triunfo y Santa Rosalía, en el Distrito Sur de la Baja California, son ejemplos del aserto anterior, cuyo dinamismo minero cambió la geografía demográfica de la media península, pues de 24.896 habitantes que había en 1878 se pasó a 42.512 en 1910, un incremento de $2.2 \%$ en promedio al año, mientras que entre 1857-1878 fue de 1.9\%. En cuanto a la transformación urbana que se vivió en esos pueblos, ésta tuvo sus matices que respondieron a su propio origen y emplazamiento. El Triunfo era una comunidad de origen colonial que desde 1822 formaba parte de la municipalidad de San Antonio, con un emplazamiento rodeado de otros pueblos que en conjunto concentraban el $75 \%$ del total de habitantes de la media península, precisamente en el momento en que se estableció la compañía El Progreso. Circunstancias que favorecieron al poder municipal encabezar el proceso de urbanización, desde definir la organización 
del espacio, el trazo arquitectónico y la introducción de los servicios públicos, sin descartar en ello un juego de negociaciones con la empresa minera.

En contraste Santa Rosalía debió su nacimiento y desarrollo al interés privado, en un emplazamiento totalmente despoblado y propiedad de la propia empresa minera. Así pues, quedó bajo la dirección de El Boleo la construcción no sólo de la infraestructura para el desarrollo de los trabajos mineros sino el enganchar a trabajadores en otras regiones del país y el extranjero, para cuya permanencia tuvo que levantar una infraestructura arquitectónica y de servicios públicos donde permeó un espíritu segregacionista, peculiaridad que se atisba igualmente en las poblaciones mineras del norte de Sonora (Romero, 2001: 284-294), cuya existencia se debió también a la explotación de la riqueza cuprífera. Concluimos este trabajo apuntando que esta impronta que dejó la minería que tuvo que ver con el proceso de urbanización sobre todo en espacios despoblados, como lo fueron algunas regiones del noroeste de México, comienza apenas a explorarse. 


\section{Archivos consultados}

» Archivo Histórico Pablo L. Martínez (AHPLM)

»Archivo General de la Nación (AGN)

» Biblioteca del Archivo General de la Nación (BAGN) 


\section{Q Bibliografía}

"Amao Manríquez, J. L. (1997). Mineros, misioneros y rancheros de la Antigua California. México, Plaza y Valdés Editores.

" Clark, David (1982). Urban geography. An introduction guide. Baltimore, The Johns Hopkins University Press.

"De Gortari, H. (1990). “Aproximaciones a lo social y lo urbano en la historiografía mexicana de las dos últimas décadas" en Memorias del simposio Mexicanista: 635-646. México, Comité Mexicano de Ciencias Históricas/ Gobierno del estado de Morelos/ Instituto de investigaciones Históricas de la UNAM.

»Del Río, I. y M. E. Altable (2000). Breve historia de Baja California Sur. México, Fondo de Cultura Económica.

》 González, E. (1985). La inversión francesa en la minería durante el porfiriato: La Cía. El Boleo, Santa Rosalía, Baja California Sur. Tesis de licenciatura inédita. Unidad Interdisciplinaria Docente de Humanidades, Facultad de Historia, Universidad Veracruzana.

》 González, E. (2000). La Compañía El Boleo: su impacto social en la municipalidad de Mulegé (1885-1918). México, UABCS/ Minera Curator, S.A. de C. V./ Colegio de Bachilleres de BCS.

» González, E. (2016). La Compañía El Boleo. Una empresa de capital francés durante el régimen porfiriano. México, UABCS.

»González, M. (1993). Los extranjeros en México y los mexicanos en el Extranjero, 1821-1970, I. México, El Colegio de México.

" González, E. e I. Rivas (2013). El gobierno del general Félix Ortega. Informes, decretos, manifiestos y actas (enero-mayo de 1915). México, UABCS.

" González, E. e I. Rivas (2014). “La minería de plata y cobre, una actividad desarrollada por extranjeros en Baja California Sur, 1856-1910" en del Río, I. y J. Vidargas (coords.), Intereses extranjeros y nacionalismo en el noroeste de México 1840-1920: 121-177. México, UNAM.

" Guerra, F. (1993). México: del Antiguo Régimen a la Revolución, I. México, Fondo de Cultura Económica.

» Herrera, I. (1998). “Cincuenta años de historia económica mexicana: los escritores de la historia minera mexicana de 19140 a 1990" en Von Wobeser, G. (coord.), Cincuenta años de investigación histórica en México: 171-177. México, Universidad Nacional Autónoma de México/ Universidad de Guanajuato.

» Kortheuer, D. (2001). Santa Rosalía and Compagnie du Boleo: The Making of a Town and Company in the porfirian frontier 1885-1900. Doctor of Philosophy thesis. University of California, Irvine. Ann Arbor, UMI films.

» Krauze, E. (1987). Porfirio Díaz. Místico de la autoridad. México, Fondo de Cultura Económica.

"Mason, J. (2002). Empire and Revolution. The Americans in Mexico since the civil war. United States of America, University of California Press.

" Morse, Richard (1971). La investigación urbana latinoamericana: tendencias y planteos. Buenos Aires, SIAP.

» Nava, G. (1965). “La minería” en Cosío, D. (coord.), Historia Moderna de México. El Porfi- 
riato. Vida Económica: 179-310. México, Hermes.

» Pipitone, U. (2003). Ciudades, naciones, regiones. Los espacios institucionales de la modernidad. México, Fondo de Cultura Económica.

» Rivas, I. (2000). El desarrollo minero en San Antonio y El Triunfo, Baja California (1856-1925). México, Colegio de Bachilleres del Estado de Baja California Sur.

» Rivera, M. (1883). México pintoresco, artístico y monumental, tomo tercero. México, Imprenta de la Reforma.

»Romero, J. M. (1991). El Boleo, Santa Rosalía, Baja California Sur. Un pueblo que se negó a morir 1885-1954). México, Universidad de Sonora/ Gobierno del estado de Baja California Sur/ Centro de Estudios Mexicanos y Centroamericanos/ Embajada de Francia en México.

» Romero, J. M. (2001). La minería en el noroeste de México: utopía y realidad 1850-1910. México, Universidad de Sonora/ Plaza y Valdés Editores.

» Sánchez de Tagle, E.; M. D. Morales y M. A. Ros (2016). La ciudad de México (1521-1857), un balance historiográfico. Relaciones 76: 17-48. Disponible en Internet: www.revistarelaciones.com/files/revistas/076/EstebanSanchezDe Tagle.pdf Consultado el 12 de agosto de 2016.

» Sariego, J. L.; L Raygadas.; M. A Gámez y J. Farrera (1988). El Estado y la minería mexicana. Política, trabajo y sociedad durante el siglo XX. México, Secretaría de Energía, Minas e Industria Paraestatal/ Instituto Nacional de Antropología e Historia/ Comisión de Fomento Minero/ Fondo de Cultura Económica.

» Taylor, L. (2007). La fiebre del oro en Baja California durante la década de 1850: su impacto sobre el desarrollo del territorio. Región y Sociedad 38: 105-127.

"Trejo, D. (2002). “Las actividades económicas" en Trejo, D. (coord.), Historia General de Baja California Sur. I. La economía regional: 187-225. México, CONACYT/ UABCS/ SEP de Baja California Sur/ Plaza y Valdés Editores.

»Velasco-Ávila, C.; E. Flores; A. Parra y C. Gutiérrez (1988). Estado y minería en México (1767-1910). México, Secretaría de Energía, Minas e Industria Paraestatal/ Instituto Nacional de Antropología e Historia/ Comisión de Fomento Minero/ Fondo de Cultura Económica.

»Vries, J. de (1987). La urbanización de Europa. 1500-180o. Barcelona, Crítica. 